\title{
Summative Objective Structured Clinical Examination Assessment: A Mini Review
}

\author{
Taiwo Akhigbe ${ }^{1^{*}}$ \\ ${ }^{1}$ Department of Emergency Medicine, Altnagelvin Hospital, Northern Ireland, UK
}

Corresponding Author: Taiwo Akhigbe, MBBS, MCh, MSc, PgD, FRSPH, Department of Emergency Medicine, Altnagelvin Hospital, Northern Ireland, UK. Tel: +44-7459712427, Email: akhigbetaiwo@yahoo.com

Received September 20, 2018; Accepted December 2, 2018; Online Published December 27, 2018

\begin{abstract}
The end of any form of rigorous, specific, and high-stakes process of systematic and structured instruction is characterized by a summative assessment to evaluate the learner's ability to apply the body of knowledge or clinical skills encountered and interacted with over a specific duration and to progress to the next phase of training. The aim of this project is to analyze the design, validity, delivery, supervision, and feedback of a summative objective structured clinical examination (OSCE) assessment. The results of this analysis showed a satisfactory and widely accepted method of assessment in medical education despite a few shortcomings. All forms of assessment have their inherent strengths and weaknesses, but it is essential that these assessments encourage future learning. Summative assessment has been proven to be a valid, comprehensive, and reliable method, and most importantly, it allows direct observation and evaluation of procedural and clinical skills.

Keywords: Clinical Examination, Medical Education, Summative Assessment

Citation: Akhigbe T. Summative objective structured clinical examination assessment: a mini review. Int J Med Rev. 2018;5(4):140-142. doi:10.29252/IJMR-050402.
\end{abstract}

\section{Introduction}

The end of any form of rigorous, specific, high-stakes process of systematic and structured instruction is characterized by a summative assessment to evaluate the learner's ability to apply the body of knowledge or clinical skills encountered and interacted with over a specific duration and to progress to the next phase of training. ${ }^{\text {T }}$ There is a significant correlation between learning outcomes and assessment planning with objective feedback for the improvement of learners. ${ }^{2}$

The goal of summative assessment is to evaluate student learning at the end of a specified period against a set standard, usually one with high stakes or high value in terms of its effect. Examples of summative assessment include objective structured clinical examination (OSCE), long case clinical exam, short case clinical exam, oral or viva exam, final projects, final essays, and many more.

All forms of assessment have their inherent strength and weaknesses, but it is essential that these assessments encourage future learning. ${ }^{3}$ The OSCE form of summative assessment has been proven to be valid, comprehensive, and reliable, and most importantly, it allows the direct observation and evaluation of procedural and clinical skills. The current project analyzed the design, validity, delivery, supervision, and feedback of summative OSCE assessment.

\section{Purpose}

The purpose of OSCE is to evaluate a candidate's abilities after a specified period of training or learning on relevant areas of the curriculum, giving all candidates the same opportunity, environment, clinical task, and structured marking scheme in a bid to reduce bias. Unlike long essays or other written exams which test cognitive knowledge, OSCE tests a broad range of skills including problem-solving, decision-making, communication, and interpersonal and patient management abilities. The OSCE is designed to test the application of knowledge regarding current and evidence-based practice and not just the recitation of facts or the regurgitation of ideas or concepts.
Design
OSCE is currently the most widely-used assessment of clinical competency in medical education. ${ }^{4}$ This assessment tool was first described twenty-nine years ago. ${ }^{5}$ The major principle behind OSCE is that all candidates are assessed with the same clinical cases or tasks over the same duration and, optimally, by the same examiner. When compared with long case assessment, there is some decline in level of bias, and OSCE tends to cover more ground. Clinical competence in postgraduate medical education is key to progress and becoming a consultant in the long run. It is not enough for one to have knowledge; the application of one's knowledge is key. Miller ${ }^{6}$ describes a conceptual framework of assessing various domains of clinical competency, and OSCE is a common way of evaluating the "shows how" of Miller's clinical competency

Copyright (C) 2018 The Author(s). This is an open-access article distributed under the terms of the Creative Commons Attribution License (http:// creativecommons.org/licenses/by/4.0), which permits unrestricted use, distribution, and reproduction in any medium, provided the original work is properly cited. 
pyramid (Figure 1).

The fundamental skill in the design of OSCE entails

- Goals of the OSCE;

- Catalog of skills to be assessed;

- Objective assessment and marking scheme;

- Recruitment and training of standardized patients, marshals, and timekeepers;

- Procurement of manikins and other simulation technologies;

- Recruitment and training of examiners;

- Recruitment of observers for effective feedback purposes; and

- Date of release of results.

\section{Validity}

The validity of an OSCE is in its capacity to measure what it is intended to measure. Hence, the OSCE is said to be valid if it measures specific clinical competencies fit for the candidate's level as intended by the examining or training body. There are different types of validity, including content validity of the OSCE, if the questions match the learning outcomes or are within the expected competencies of the candidate's level. Criterion validity depicts the extent to which the OSCE measures the outcome, whether all aspects of the curriculum were represented in the OSCE or only a few aspects were emphasized. It is a strong tool for assessing system-based practice and practice-based learning and improvement because of its high predictive validity and impact on doctors' training.

\section{Reliability}

The reliability of a test is the measure of its reproducibility and accuracy, which connotes the level to which the test consistently measures the outcome (OSCE versus level of clinical competency). OSCE is accepted as a generally reliable form of clinical assessment, especially when used by multiple examiners and with a highly structured marking scheme to further reduce the element of bias. Moreover, there is a significant generalizability of use of the OSCE.

\section{Delivery}

This is no singular pattern of delivery as it varies from one institution to another, but the principle and philosophy of OSCE remains the same. In the current case, candidates were

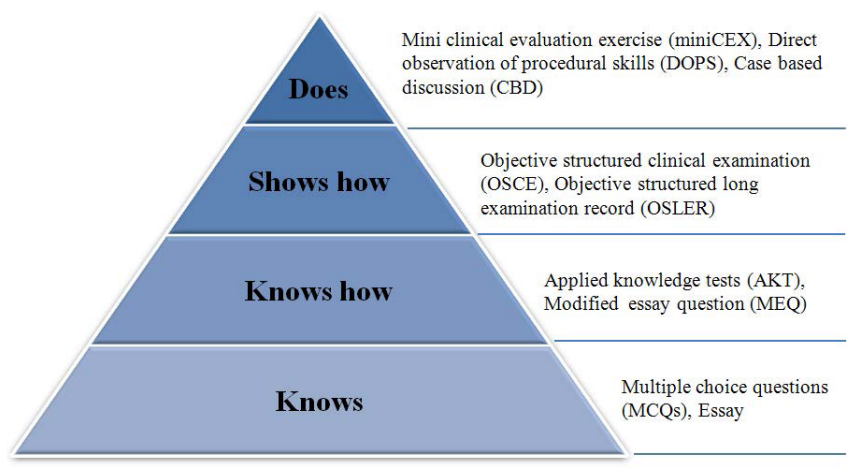

Figure 1. Miller Pyramid of Clinical Competency systematically rotated within ten stations (with an additional two rest stations) which included all aspects of clinical competence, like communication skills and professionalism, breaking bad news, history taking and clinical examination, data interpretation and drug management, critical care and resuscitation. The stations were real or simulated patients with the use of manikins, and each station had a duration of ten minutes. Simulated patients can be expensive and difficult in terms of training and understanding exam concepts, especially in pediatric stations which may be difficult to mimic. ${ }^{8}$ In addition, simulated patient validity in clinical practice is rarely distinguished from real patient. ${ }^{9}$

Logistically, enough space in which to conduct the OSCE is required. Each station space should accommodate the candidate, an examiner, and the simulated patient or manikin. A large clinic room would be ideal.

\section{Cost Effectiveness}

The OSCE assessment is expensive to run, because it requires multiple examiners, especially for large numbers of candidates. In addition to recruiting real patients, the use of simulated patients in the form of manikins can be very expensive, especially for low resource areas. Other factors are accommodations (either hotel or stadium is usually preferred, depending on the candidate population), equipment (leasing or purchasing), examiner's fees, and refreshments. Highstakes exams like the summative OSCE can be very expensive to run. According to a recent study, over $£ 65000$ is required to conduct OSCE for 2 days for 185 students; with indirect costs, the expense rises above $£ 80000 .^{10}$ The use of exam software in OSCE can lead to cost effectiveness. This has been a significant challenge to the effective execution of an OSCE, especially in low resource countries.

\section{Educational Impact}

Assessment is a significant pillar of medical education, because it drives learning and has a powerful influence on future learning. ${ }^{11}$ Conversely, a study by Rudland et al in 2008 showed that OSCE does not drive learning in a predictable way in the clinical setting, but collaborative learning and OSCE are said to be more a test of psychomotor skills than a marker of clinical experience. ${ }^{12}$

\section{Acceptability}

Currently, OSCE is majorly acceptable as the best objective assessment tool in medical education. Given the significant bias associated with long case assessment, OSCE has become the most widely-accepted method of assessment and the most common method of summative assessment in medical education globally. ${ }^{13}$

\section{Feedback}

Feedback is key to professional development in a competencybased examination, especially in failed attempts where the candidate may be required to remake an attempt or is unsure of the reasons for failure. This can reinforce further learning and the effective correction of deficiencies. Studies have shown 
that immediate feedback following OSCE has led to prompt improvement and a sterling performance in the ensuing attempt. ${ }^{14}$ There should be a standard feedback mechanism where each student's performance per station is analyzed in different stages of the exam with an overall rating for each candidate made available to the candidate when requested. It is also essential that a feedback form should be completed after the exam for quality control and improvement.

\section{Conclusions}

All forms of assessment have their inherent strengths and weaknesses, but it is essential that these assessments encourage future learning. Summative OSCE assessment has been proven to be valid, comprehensive, and reliable. Most importantly, it allows direct observation and evaluation of procedural and clinical skills. In addition, immediate feedback following summative OSCE has a significant capacity to produce great improvement and excellent performance in subsequent assessments.

\section{Conflict of Interest Disclosures}

The author declares that there is no conflict of interest.

\section{References}

1. Rust C, Price M, O'Donovan B. Improving students' learning by developing their understanding of assessment criteria and processes. Assess Eval High Educ. 2003;28(2):147-164. doi:10.1080/02602930301671.

2. Ende J. Feedback in clinical medical education. JAMA. 1983;250(6):777-781. doi:10.1001/jama.1983.03340060055026.

3. Ben-David MF. The role of assessment in expanding professional horizons. Med Teach. 2000;22(5):472-477. doi:10.1080/01421590050110731.
4. Newble D. Techniques for measuring clinical competence: objective structured clinical examinations. Med Educ. 2004;38(2):199-203. doi:10.1111/j.1365-2923.2004.01755.x.

5. Harden RM, Gleeson FA. Assessment of clinical competence using an objective structured clinical examination (OSCE). Med Educ. 1979;13(1):41-54. doi:10.1111/j.1365-2923.1979.tb00918.x.

6. Miller GE. The assessment of clinical skills/competence/ performance. Acad Med. 1990;65(9 Suppl):S63-S67. doi: 10.1097/00001888-199009000-00045.

7. Martin IG, Jolly B. Predictive validity and estimated cut score of an objective structured clinical examination (OSCE) used as an assessment of clinical skills at the end of the first clinical year. Med Educ. 2002;36(5):418-425. doi:10.1046/j.13652923.2002.01207.x.

8. Prislin MD, Fitzpatrick CF, Lie D, Giglio M, Radecki S, Lewis E. Use of an objective structured clinical examination in evaluating student performance. Fam Med. 1998;30(5):338-344.

9. Harden RM. Twelve tips for organizing an Objective Structured Clinical Examination (OSCE). Med Teach. 1990;12(3-4):259-264. doi:10.3109/01421599009006629.

10. Brown C, Ross S, Cleland J, Walsh K. Money makes the (medical assessment) world go round: The cost of components of a summative final year Objective Structured Clinical Examination (OSCE). Med Teach. 2015;37(7):653-659. doi:10.3109/014215 9x.2015.1033389.

11. Van Der Vleuten CP. The assessment of professional competence: Developments, research and practical implications. Adv Health Sci Educ Theory Pract. 1996;1 (1):41-67. doi:10.1007/bf00596229.

12. Rudland J, Wilkinson T, Smith-Han K, Thompson-Fawcett M. "You can do it late at night or in the morning. You can do it at home, I did it with my flatmate." The educational impact of an OSCE. Med Teach. 2008;30(2):206-211. doi:10.1080/01421590701851312.

13. Ponnamperuma GG, Karunathilake IM, McAleer S, Davis MH. The long case and its modifications: a literature review. Med Educ. 2009;43(10):936-941. doi:10.1111/j.1365-2923.2009.03448.x.

14. Hattie J, Timperley H. The power of feedback. Rev Educ Res. 2007;77(1):81-112. doi:10.3102/003465430298487. 